\title{
Cold Adaptation
}

National Cancer Institute

\section{Source}

National Cancer Institute. Cold Adaptation. NCI Thesaurus. Code C157200.

The process by which the form or structure of an organism or a bioactive molecule is modified to survive or have activity in a low temperature environment. 